\title{
Leadership mindset regarding talent management practices: A case study of the City of Windhoek Council
}

\begin{tabular}{|c|c|}
\hline \multicolumn{2}{|c|}{$\begin{array}{l}\text { Authors: } \\
\text { Selma N. Shingenge }{ }^{1} \text { (D) } \\
\text { Musawenkosi D. Saurombe }^{2} \text { (D) }\end{array}$} \\
\hline \multicolumn{2}{|c|}{$\begin{array}{l}\text { Affiliations: } \\
{ }^{1} \text { Department of } \\
\text { Management, Southern } \\
\text { Business School, } \\
\text { Johannesburg, South Africa }\end{array}$} \\
\hline \multicolumn{2}{|c|}{$\begin{array}{l}{ }^{2} \text { Department of Industrial } \\
\text { Psychology and People } \\
\text { Management, College of } \\
\text { Business and Economics, } \\
\text { University of Johannesburg, } \\
\text { Johannesburg, South Africa }\end{array}$} \\
\hline \multicolumn{2}{|c|}{$\begin{array}{l}\text { Corresponding author: } \\
\text { Musawenkosi Saurombe, } \\
\text { donaynaysauz24@gmail.com }\end{array}$} \\
\hline \multicolumn{2}{|c|}{$\begin{array}{l}\text { Dates: } \\
\text { Received: } 16 \text { July } 2021 \\
\text { Accepted: } 07 \text { Dec. } 2021 \\
\text { Published: } 25 \text { Feb. } 2022\end{array}$} \\
\hline \multicolumn{2}{|c|}{$\begin{array}{l}\text { How to cite this article: } \\
\text { Shingenge, S.N., \& Saurombe } \\
\text { M.D. (2022). Leadership } \\
\text { mindset regarding talent } \\
\text { management practices: } \\
\text { A case study of the City } \\
\text { of Windhoek Council. SA } \\
\text { Journal of Human Resource } \\
\text { Management/SA Tydskrif vir } \\
\text { Menslikehulpbronbestuur, } \\
\text { 20(0), a1730. https://doi. } \\
\text { org/10.4102/sajhrm. } \\
\text { v20i0.1730 }\end{array}$} \\
\hline \multicolumn{2}{|c|}{$\begin{array}{l}\text { Copyright: } \\
\text { (C) 2022. The Authors. } \\
\text { Licensee: AOSIS. This } \\
\text { is licensed under the } \\
\text { Creative Commons } \\
\text { Attribution License. }\end{array}$} \\
\hline \multicolumn{2}{|l|}{ Read online: } \\
\hline 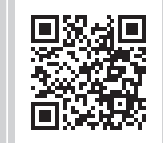 & $\begin{array}{l}\text { Scan this QR } \\
\text { code with your } \\
\text { smart phone or } \\
\text { mobile device } \\
\text { to read online. }\end{array}$ \\
\hline
\end{tabular}

Orientation: Municipalities are facing significant challenges in attracting talented personnel because of poor talent management practices.

Research purpose: The main objective of this research was to determine how effective the leadership mindset is regarding talent management in Windhoek City Council in Namibia.

Motivation for the study: Limited research currently exists on the outlook that leaders have in municipalities regarding talent management practices.

Research approach, design and method: A qualitative approach was adopted for this study; semi-structured interviews were conducted to gain data. The participants were six top staff members from Human resource division in the City of Windhoek Council in Namibia. In addition, data were analysed through content-thematic analysis.

Main findings: The findings of this study showed that effective talent management practices are crucial for an organisation to attract and retain skilled and experienced workers to reach a sustainable competitive advantage. The study revealed specific elements that constitute sound leadership mindset regarding talent management. These were talent management practices, leadership mind-set, recruitment strategy/talent acquisition and talent retention strategy.

Practical/managerial implications: If individuals' talents are not harnessed because of poor leadership and a lack of sound mindset and commitment to talent, this will negatively affect talent management in organisations. Thus, the findings of the study challenge the government to formalise the draft talent management policy at municipalities to help municipalities remain competitive through attracting, developing, retaining and rewarding talented employees.

Contribution/value-addition: The study provides important insights that could assist the City of Windhoek Council and the government at large to attract talented personnel and become an employer of choice.

Keywords: leadership mind-set; talent recruitment strategy; talent acquisition; talent management practices; talent retention strategy.

\section{Introduction}

\section{Orientation}

The talent management mandate is to source, keep, enhance and reward people whilst ensuring that they perform the tasks allotted to them. Barkhuizen and Gumede (2021) state that talent management is a strategic process that is pivotal in ensuring the sustainability and success of an organisation. Nguwi (2015) suggests that regardless of the money invested into a business, some of these organisations still do not perform. The blame is usually shifted on the economic environment, whilst the actual reason is the absence of employees with the right skills and talent, which is a requirement for the success of any given organisation.

Several researchers have found that applying talent management practices is still a major challenge for organisations in the public sector. A study conducted by Spreitzer, Cameron and Garrett (2017) indicated that individuals leave employment in local government organisations for greater career enhancement opportunities elsewhere. In addition, a study conducted by Saurombe and Barkhuizen (in press) found that talent management practices, for example, talent development, workforce planning, strategies for employee retention, were being poorly applied amongst supporting staff in a public institution in South Africa and consequently had a negative effect on their service orientation and work engagement. 
In a local municipality study conducted by Mabope (2018), it was found that most of its managers are not competent in human resource aspects, for example, recruitment and selection, compensation, organisational development, performance management and safety and wellness. Horton (2016) asserts that talent management is considered as being centred on the use of top-level human capital planning tools to create organisational competencies and to make sure that the business has skilled and experienced workers needed to reach a sustainable competitive advantage. If the staff are not developed, they may end up leaving in search of development at other organisations. Adzido, Dzogbede, Kamasah and Dzineku (2015) noted that investing in the development of staff has the advantage of benefitting not only talented staff but also the entire organisational workforce.

Saurombe, Barkhuizen and Schutte (2017) posited that the initial idea regarding talent mindset was concerned with the extent of accountability that a leader is willing to accept within the organisation, concerning talent management. An effective leader accepts that if others fail, it will also reflect on them, and thus, they take the initiative to understand and contribute towards the performance and functioning of the organisation. The mindset of an individual is so important given that it governs how they interpret and think about situations, their reactions emotionally, the decisions they make and actions that are taken. The mindset of individuals directly has an impact on their relationships, their subsequent interactions and how they lead. It also sets the direction for the business and determines the type of experience the workers have in their place of work.

\section{Research purpose and objectives}

The primary aim of the study was to determine how effective the leadership mindset is regarding talent management at the City of Windhoek Council in Namibia.

The study further aimed to:

- to determine the importance of effective talent management in the Windhoek City Council in Namibia.

- to determine the importance of a leadership mindset regarding talent management in local authorities.

- to determine the effectiveness of the current recruitment strategy of the Windhoek City Council in Namibia.

- to determine the effectiveness of the current talent retention strategy of the Windhoek City Council in Namibia.

\section{Research questions}

The main question this research sought to answer was: how effective is the leadership mindset regarding talent management at the City of Windhoek Council in Namibia? The main research questions were:

- what is the importance of effective talent management at the Windhoek City Council in Namibia?

- what is the importance of sound leadership mindset regarding talent management in local authorities?
- what is the effectiveness of the current recruitment strategy of the Windhoek City Council in Namibia?

- what is the effectiveness of the current talent retention strategy of the Windhoek City Council in Namibia?

\section{Literature review}

\section{The background of the City of Windhoek Council}

According to Hanns Seidel Foundation (2018), the City of Windhoek Council is a government entity that is governed by the Local Authorities Act. It, thus, forms part of the government sphere, based in the Khomas region. The City of Windhoek Council is co-operatively run by administrative and political authorities. These leaders have an overall mandate to provide services to the citizens. Local authorities have the fiduciary duty and power to make regulations on a wide range of issues (Bwowe, 2015). Some of the services that the municipality provides are roads, water supply, electricity, the removal and disposal of refuse to the community as well as human settlements that were established formally as residential areas that consist of neighbourhoods where the local authority has laid out streets and divided the land into plots that are made available for purchase (Bwowe, 2015).

When any local authority is not able to carry out its mandate, the central government may take steps to solve the problem (Hanns Seidel Foundation, 2018). The Windhoek report implies that $40 \%$ of the city's population is unemployed, because of a lack of skills and aggravated by the lack of higher institutions emanating from the colonial era. To provide quality services to the community requires committed and talented people (Masale, Barkhuizen, \& Schutte, 2021). The findings of this research can, thus, be useful to the municipality of Windhoek.

\section{Talent management practices in local authorities}

The process of talent management covers all the important aspects of an employee's life cycle, which are recruitment and selection, enhancing their knowledge by providing appropriate training, performance management and succession planning for the future (Sareen \& Mishra, 2016). Top management and the HR managers have always focused on basic talent management but to reach the desired levels of success; they require committed, engaged and highperforming employees (Saurombe et al., 2017).

Talent management helps to discover the strengths and weaknesses of their employees. Talent management recognises both people who excel at a particular activity and enables them to put more effort towards their work that then improves their capabilities and helps them focus on meeting the organisational goals (Barkhuizen \& Gumede, 2021). Thus, talent management contributes to the effective management of the local authorities in Namibia. Saurombe and Barkhuizen (in press) opined that to grow fast and to achieve high performance, all the organisations need to incorporate effective talent management strategies. They also showed that the companies that consider talent 
management as a strategic activity will achieve greater success levels and will also be able to sustain them in the long run. The study also concluded that talent management is not merely an initiative of the human resource department, but it is an integral part of the overall development of the organisation.

According to Nguwi (2015), the organisation needs to put in place talent management mechanisms to get maximum output from employees because the success of the organisation depends on the performance of employees and is directly related to the quality of the workforce and the service that the organisation provides. The Masvingo City Council in Zimbabwe is responsible for the provision of water, waste management, maintenance of council infrastructure and town planning, amongst other services, to the Masvingo residents. If these services are not up to standard, there will be a huge outcry from community members (Mahlahla, 2018).

The study focused on the local authority's employees, how effective talent management could influence their ability to provide efficient service delivery, as well as retain valued employees. Namibian local authorities have the power to make local regulations on a wide variety of matters. All local authorities must supply water, sewerage and refuse disposal services to communities, formally established as residential areas, including neighbourhoods where the local authority has laid out streets and divided the land into plots available for purchase (Mabope, 2018).

Aina and Atan (2020) stated that the organisations that have talent management practices in place have enhanced performance and productivity, and to achieve this, they need to develop a high performing workforce to fill the top positions. Talent management practices are to be taken into consideration in a local authority for career planning and effective workforce. Proper measures should be taken to implement the best talent management practices in the industry, which will help the organisation to gain a competitive edge over the competitors and will help the company to always stay ahead in the market (Aina \& Atan, 2020).

\section{Importance of effective management in local authorities}

For organisational leaders to effectively manage talent within the organisation, they need to acknowledge the critical role that talent plays towards the overall effectiveness of the organisation (Saurombe et al., 2017). Management needs to carry out their roles of planning, leading organising and controlling well so that they can manage talent effectively (Barkhuizen \& Gumede, 2021). Therefore, effective management is needed to help the City of Windhoek Council to identify and retain talent who will be able to fulfil the municipality's administrative mandate of supplying goods and rendering quality services to citizens. Thus, the study considers that effective management is important in the local authorities.

\section{Talent management recruitment strategies}

Saurombe et al. (2017) describe talent acquisition as discovering the appropriate talent when it is required and ensuring a consistent applicant experience throughout the process of attraction, recruitment, appointment and induction. The extent to which an organisation is effective largely depends on the effectiveness of the organisation's employees. The underlying idea behind talent management holds that the right employee should be recruited for the right job. Maheshwari and Haque (2020) identified the importance of competency-based recruitment practices. The previous study argued that attraction and selection of talent require a flexible and well-designed competency-based recruitment system for various sections of workforce. The competency-based recruitment system is the starting point towards the management of talent in any organisation. Once the recruitment system in any organisation is streamlined, the second phase of talent management would be proper training and development of employees. Talent management is a useful tool when it describes an organisation's commitment to hire, manage, develop and retain talented employees. It comprises all the work process and systems that relate to retaining and developing a superior workforce (Barkhuizen \& Gumede, 2021).

Corroboratively, Jackson and Schuler (2017) viewed talent management as the job of ensuring the right person is in the right job at the right time. When hiring, managers need to have a set list of skills and qualifications they are looking for. Anyone who fulfils them should be granted an interview, no matter what is his or her age. Talent management of employees will start with the selection process. Therefore, it is important to appoint the right person in the right job. In this process, career development strategies for different generations in the workplace need to be considered (Horton, 2016). Organisations need to understand how their employees will behave in future and get them to behave differently from the past to get better results. The greater the efforts that organisations put into recruiting employees, the greater the likelihood of retaining those employees (Saurombe et al., 2017). The goal of talent management practices or programs implemented by the company must be to get the right people for the right jobs to make the company successful (Sareen \& Mishra, 2016); however, this goal is not as easy to achieve as it sounds.

\section{Talent management retention strategies}

According to Chilvers et al. (2019), retention strategies are policies and plans that organisations follow to satisfy the diverse needs of employees and create an environment that encourages people to stay in the organisation. Talent management is a human resource doctrine that holds that the employee is not merely a means to achieve organisational objectives but an organisational asset, hence the term human capital. As such, organisations are moving away from the traditional methods of managing their human capital, and in contemporary times, organisations look more intently at 
ways of retaining their human capital. It should be noted that the money spent on developing human capital is, at times, significant and the loss of an employee would translate to a loss of money and no return on investment (Aina \& Atan, 2020).

Employees want to feel that their abilities are utilised and valued. Jackson and Schuler (2017) stated that placing employees in talent-fulfilling positions benefits both employees and employers. Employees who feel valued at work achieve greater productivity than those who feel like their talent is being wasted (Sareen \& Mishra, 2016). The retaining of critical employees that are productive is a big challenge for both domestic and international institutions given that the disturbance created by the replacement of individuals who will voluntarily exit the institution is costly for the business indirectly and directly (Schlechter, Syce, \& Bussin, 2016).

Individuals generate value using the organisation's resources. This means that the more effective the individuals become, the better the chance of the organisation performing. Unfortunately, if individuals' talents are not harnessed because of poor leadership and a lack of sound mindset and commitment to talent, this will negatively affect talent management in organisations. This statement has been confirmed in a study by Saurombe et al. (2017), who reported that many executives do not have ample time to strengthen talent pools and are also not trained on how to develop and nurture talent. Many organisations have now come to the realisation that the growth of the organisation and its subsequent effectiveness depend on programs aimed at career development, which ensures that the needed talent and skill sets are present and applicable in the job market (Schlechter et al., 2016).

Similarly, Sareen and Mishra (2016) found out that the easiest way to ensure employees feel respected is to make sure managers regularly talk with them about their jobs and enquiring what the company could do to help them achieve the goals. They felt that talent management processes that maintain accountability improve workforce productivity. They align employee behaviours with business goals by creating connections between what people do on the job and what they receive from the company. Companies can take advantage of this basic truth by ensuring that people see clear connections between what they do on the job and the rewards they receive from the company. This requires establishing, communicating and following processes that directly link employee performance to pay, job opportunities, promotions and other employment decisions (Masale et al., 2021).

Maintaining accountability also increases employee commitment towards the company by creating an organisational culture that is perceived to be fairer and more equitable (Masale et al., 2021). Top management at the City of Windhoek Council should ensure that the retention strategies adopt the commitment-based approach. The essence of the commitment-based approach is to draw out employee commitment, which in turn will produce both better organisational performance and greater human development.

Chilvers et al. (2019) highlighted the importance of talent retention by saying that effective talent management and retention is a continuation process, and it must be the part of the organisational culture. This study, therefore, sought to determine how best talent can be retained, despite the development process that may render this talent more attractive to other competing organisations.

\section{Research design Research approach}

This research used the phenomenological and case study research paradigms to explore the perceptions as well as the relationship between leadership mindset and talent management practices in the City of Windhoek Council. Phenomenological research is a qualitative approach wherein the views of a few participants on a specific phenomenon are collected to better understand these participants' perceptions of a particular phenomenon (Bryman \& Bell, 2017).

This study also used a case study approach to effectively address the phenomenon under investigation at the City of Windhoek Council in Namibia. Sutton and Austin (2015) explain that case studies are useful when 'how' and 'why' questions are posed. The study explored and gained deeper understanding about how effective the current leadership mindset regarding talent management is at the City of Windhoek Council in Namibia. A case study strategy was deemed most appropriate as the researchers aimed to investigate a contemporary phenomenon in the real-life context (Bryman \& Bell, 2017).

\section{Research strategy}

The researchers applied for ethical clearance that was granted by the University (Southern Business School). The main researcher emailed a letter asking for permission to collect data at the City of Windhoek Council. The letter explained the area of investigation, data collection method, ethical considerations, as well as the participants to be interviewed.

Before the interview, the participants were informed that the information will be used for research purposes only and will, therefore, be confidential. Only those who agreed to participate in the study were selected. Participant's real names were not used. Only the pseudo names Participants 1 up to 6 .

\section{Research method Research setting}

Interviews took place in Windhoek, where the main researcher travelled to interview six human resource personnel at the City of Windhoek Council premises. The interviews were administered one-on-one and face-to-face in 
the comfort of the participants' work/office environments. The interviews were all conducted in English.

\section{Entrée and establishing researcher roles}

The main author/researcher wrote up the literature and conducted the data collection of this study, whilst the second author/researcher analysed the data and discussed the findings according to emerging themes. Permission was requested from the City Council Human Resource Manager in Windhoek to conduct the interviews. After permission was granted, the researchers reached out to the prospective participants and scheduled an interview with each of them, according to availability and willingness.

\section{Research participants and sampling methods}

This study used non-probability sampling and Sutton and Austin (2015) state that in this method, the chance of selecting population elements to include in a sample is unknown. This research used purposive sampling to select six participants from the human resources department at the City of Windhoek Council, which conformed to the qualitative sample size recommendations by Braun and Clarke (2021a), and further considered the study by Guest, Bunce and Johnson (2006), which found that $94 \%$ of most prominent or frequent codes emerge in the first six interviews and $97 \%$ by 12 interviews, thus implying sufficiency of the sample size to ensure valid findings, and arguably alluding to data saturation. Purposive sampling has an advantage in that the researcher will be able to purposefully select knowledgeable staff to give detailed information about talent management. The inclusion criteria for this study were human resource managers at the City of Windhoek Council, between the ages of 18 and 65 years, with a minimum of 5 years of work experience. The work experience was critical in ensuring more pertinent contributions regarding talent management perspectives.

\section{Data collection methods}

There are many ways of collecting data, and they depend on the purpose and aim of the study. Qualitative data collection methods differ in that they consist of semi-structured or unstructured techniques. Some methods include focus groups (group discussions), individual interviews and participation/observations (Korstjens \& Moser, 2018). In addition, Brewerton and Millward (2018) stated that primary data are personally collected by the individual conducting the research using tools such as questionnaires, experiments, interviews and observation.

The researchers used an interview guide that provided a list of questions to solicit answers from participants. All questions were open ended and designed in such a way to explore the perceptions of participants on the matter of talent management. The researchers, therefore, drafted the questions in line with the research objectives.
The following questions were asked during the interviews:

- How do you generally view talent management practices in your organisation?

- To what extent are municipal leaders aware, understand and apply talent management practices to attract and retain employees in the organisation?

- What do you think is the importance of effective talent management in your organisation?

- What do you think have been the challenges of leaders in applying talent management practices?

- What do you think is the importance of leadership in improving talent management in local authorities?

- What can a municipality do to attract the best employees through effective talent management practices?

- How will better talent management help to ensure better recruitment practices in your organisation?

- In your opinion, how effective is the current talent retention strategy in your organisation?

- In your opinion, how best can talent in your organisation be retained so that they do not leave for other organisations?

\section{Data recording}

The interviews were recorded using a smart phone, voice recorder and transcribed immediately using Microsoft Word software. Data were transcribed verbatim (word for word) and saved on the computer as well as on secondary storage specifically the external hard drive, which were stored safely so that the quality of the data is not compromised. The main researcher wrote additional information in the notebook about what was being discussed to have additional backup in case of the computer or external hard drive getting corrupted or lost.

\section{Strategies employed to ensure data quality and integrity}

Ensuring the integrity of the research data is very important for promoting the quality of the study. To check the validity and reliability of the interview guide, the main researcher conducted a pilot study by interviewing one participant before conducting the final research. This was done to check any mistakes or inconsistencies in the interview guide.

The researchers further employed the following strategies to ensure the quality and rigour of the data in this research (Hadi \& Closs, 2015):

- Triangulation: the researchers discussed the generated codes and themes with other researchers to ensure credibility and conformability.

- Self-reflection: the researchers clearly stipulated their role in terms of the study and were careful of any bias that could have emanated from personal or subjective viewpoints.

- Peer-debriefing: the researchers consulted with two other researchers who were not directly involved in the study, to promote reliability and validity. 
- Extensive description: the researchers provided extensive descriptions of the research setting, sample traits, including the data gathering and analysis techniques in this study.

\section{Data analysis}

The purpose of data analysis is to organise, provide structure to and elicit meaning from research data. The study followed the thematic analysis explained by Bengtsson (2016), to record interviews, transcribe, read and review transcriptions thoroughly. According to Braun and Clarke (2021a), thematic analysis has six stages: familiarisation with the data, coding, generating initial themes, reviewing themes, defining themes and writing up the narrative or dissertation.

After transcription, the researcher read and reviewed the transcribed notes to generate codes that would be of interest to the study. Similar responses were coded and for the sake of maintaining anonymity and confidentiality, the participants' names and titles were not used but rather participants were coded as Participants 1, 2, 3, 4 and 5 .

After coding, the researcher searched for and identified themes that could be relevant for the information transcribed. These themes were identified through the questions asked during the interview process. Similar information given by participants was grouped together, and the researcher had to make sure that themes are selected according to the general patterns identified in the data provided.

\section{Reporting style}

The various themes and sub-themes that emanated from the study were delineated in the findings section of this research and were narrated and substantiated along the lines of the existing literature, where some findings were seen to be corroboratory to previous research, whilst others were contradictory, and in some cases, novel.

\section{Findings}

Four themes emerged from the thematic content analysis that was done on the semi-structured interview responses, conducted at the City of Windhoek Council premises. These are talent management practices, leadership mind-set, recruitment strategy/talent acquisition and talent retention strategy.

\section{Theme 1: Talent management practices}

During the interviews that took place at the City of Windhoek Council premises, all participants agreed unanimously that there is no formalised or approved talent management policy or framework. However, they revealed that there is a draft talent management strategy and framework, which was drafted by Niklaas Seibeb in August 2013. The draft indicated that the talent management strategy was designed to facilitate and promote the achievement of the organisational objectives through a process of identifying, attracting, nurturing and retaining talent across the entire organisation.

In addition, after being asked about the current state of talent management practices in the organisation, all participants indicated how important talent management is to the survival of the City Council. Participant 1 stated that:

'[T]he Council has not implemented a formal talent management programme. It is important to implement the policy and have talent management programmes that will identify talent in the organisation. It would be beneficial for the organisation to groom the talent in our organisation. These individuals can then ultimately add to the success or the achievement of our strategic goals.' (Participant 1, female, 46)

Participant 2 supported this view by adding the following:

'We have a talent management framework, but I don't know whether it is approved or not. We did not revise it, but we are practicing talent management indirectly. I attended a talent management course in July this year and I have realised how important it is. The talent management programme has to be rolled out but it should be very holistic. Once the framework is formalised it is important to work with people when they enter the organisation and maintain good relations with them throughout to make sure that everything works good. Each individual is different and must be developed using a holistic approach.' (Participant 2, male, 52)

In support of this view, Participant 3 said:

'We have talent management policy in place in black and white, but it is not officially adopted by the Council because we follow government regulations. The Council cannot do anything except to wait for government approval. However, it is important to formalise the process so that the Council can become more lucrative and that internal human resources processes can become easy to follow.' (Participant 3, male, 49)

Furthermore, Participant 4 added the following:

'We do have Talent management policy but not yet approved since everything is governed by the government. We are the human resources department and somehow Talent Management (TM) is being practiced indirectly although it is not yet approved.' (Participant 4, male, 38)

Participants were also asked to explain how they view the importance of current talent management practices in the Council. There were differing views on this aspect. Participant 1 said:

'Talent management is important because we are operating in a competitive environment. Therefore, we used talent management so that we can attract the right people with the right or critical skills.' (Participant 1, female, 46)

Participant 6 added:

'Our organisation needs to realise that competition for talent against the private sector is still stiff and we need to be more intentional about our talent management practices as we already have to deal with $[u \mathrm{hm}]$ the stereotypical notions [that government entities mostly attract 'lazy' people with no drive nor ambition] of prospective employees regarding government.' (Participant 6, female, 40) 


\section{Theme 2: Leadership mindset}

Leaders or managers can view talent management positively or negatively, and their perceptions are very important in ensuring the overall success of talent management. Participant 2 shared the following view:

'Leadership is affected by their mindset or perceptions of the organisation as well as talent management processes. Every organisation has its challenges, but we feel that we have a very good and strong leadership team in our HR. We also have a very strong Chief Executive Officer (CEO) who is performance driven.' (Participant 2, male, 52)

Moreover, Participant 3 posited that leadership plays a very important role in any organisation. It was further cited that the performance management system is also very important. They added that it is important for leaders to begin to think differently about how to manage talent including how to accommodate the young generation. The world is evolving, and thus nowadays more and more younger people are taking up critical positions. Thus, every leader should be able to innovate new ways of adapting to the generational gap. Both old and younger employees have different belief and value systems with regard to work and a leader should know how to cater for the needs of both groups of workers. (Participant 3, male, 49)

\section{Participant 6 added:}

'Our leadership do[es] their best to encourage, you know, a culture of acknowledging the importance of talent management. For instance, there are programs targeted at enhancing employee skills and ensuring, uhm, ongoing learning. It helps employee keep abreast with the ever-changing requirements of their jobs, especially amid the evolving technological age.' (Participant 6, female, 40)

\section{Theme 3: Talent recruitment strategy}

In terms of recruitment, most participants highlighted that the municipality follows the government mandate on how to recruit employees. They indicated that the local authorities act is a government act and highlights how staff should be recruited. The municipality always needs skilled workers such as engineers. Participant 2 shared the following:

'There is a gap in recruitment or acquisition of talent and the Council needs to work on this once the framework is formalised.' (Participant 2, male, 52)

\section{Furthermore, Participant 5 indicated the following:}

'Talent acquisition is the process of finding and acquiring skilled human labour for organisational needs and to meet any labour requirement. I believe that our recruitment strategy is fair and transparent as we have to follow government procedures.' (Participant 5, male, 43)

Participant 6 also indicated:

'Over and above following or $[u h m]$, adhering to the available legislation, I think our organisation could improve its recruitment strategy by perhaps considering best practices in the private sector. Well, unfortunately it seems government entities are always lagging compared to private entities in terms of, you know, these recruitment strategies.' (Participant 6, female, 40)

\section{Theme 4: Talent retention strategy}

The participants unanimously agreed that there is no formal retention strategy, but they believe that their turnover rate is one of the lowest amongst the municipalities as well as other private organisations in Namibia (less than $5 \%$ of employees recruited leave), and some employees have even worked for the organisation for more than 20 years. Participants cited that some of the reasons why the turnover rate is low are because they have a very good salary in line with market rates, good working conditions, good study programmes and excellent fringe benefits such as housing allowances, car allowances, annual leave, medical aid scheme and lucrative pension schemes to name a few. Participant 3 said:

' $[W]$ e do not have a talent retention strategy in place. But we do have one of the most competitive salary packages and benefits which allow us to have a low turnover rate. The workers who put more effort should be rewarded, promoted, or be developed so as to retain them.' (Participant 3, male, 49)

Moreover, to keep and develop skilled workers, the municipality is making use of in-house training as well as outside trainings. For example, Participant 4 said:

'W] recruit final year engineering students whom we attach to senior engineers so that there is skills transfer. In this way, we also make sure that there is no skills shortage when a senior engineer resigns or leaves the organisation.' (Participant 4, male, 38)

\section{Sub-theme: training and development}

The study unearthed the perceived significance of training and development in enhancing retention odds. Participant 1 highlighted the importance of providing career development to employees:

' $[P]$ roviding learning and development opportunities that helps employees to achieve their long-term career goal is a talent management best practice and can increase employee satisfaction and company loyalty. HR has the opportunity to have a positive impact on nearly every point of the employee lifecycle.' (Participant 1, female, 46)

\section{Participant 5 concurred and said:}

' $[W]$ e have good benefits such as a study skills programme where the company pays for employees study. If they study something in their field of work, the company pays them $100 \%$ of the tuition fees for the study. If it is not in their field they are not refunded.' (Participant 5, male, 43)

Participant 3 further added the following:

' $[I] \mathrm{t}$ is very rare for our workers to leave just like that. People coming to work here, stay here. A lot of people when they come here they don't leave the organisation.' (Participant 3, male, 49)

\section{Discussion Outline of the findings}

The main objective of this research was to determine the current leadership mindset regarding talent management in the City of Windhoek Council in Namibia. To meet this objective, the study addressed the following objectives: to 
determine the importance of effective talent management in the Windhoek City Council in Namibia, to determine the importance of a leadership mindset regarding talent management in local authorities, to determine how effective the current recruitment strategy of the Windhoek City Council in Namibia is and to determine how effective the current talent retention strategy of the Windhoek City Council in Namibia is.

When the human resources personnel were asked about their perception of talent management, they agreed that a positive mindset towards talent management is critical for the success of an enterprise. Contrary to this, Masale et al. (2021) discovered in their study of local government institutions that middle management does not have a good perception of how talent management practices are being applied. The previous authors stated that employees leave because of lack of commitment of executives towards talent management.

In addition, the findings that emerged from the study show that there is no approved talent management policy in the City of Windhoek Council. There is a draft talent management framework in place, but it has not yet been approved by the government. Thus, the municipality cannot use it effectively to develop and retain talent within the enterprise. This result is confirmed by several authors who concur that some municipalities are struggling to deliver quality services to communities because of lack or poor application of talent management practices (Bwowe, 2015; Mahlahla, 2018).

The City of Windhoek Council does not have recruitment and retention strategies in place. A study done by Namweda (2017) confirmed that if an organisation does not have these strategies in place, they will not gain a competitive advantage in recruiting and retaining the best staff members. On the positive side, it appears that the City of Windhoek Council has a very low turnover rate because it offers good remuneration packages as well as having career advancement plans in place. This, however, is not the case with some municipalities as Bwowe (2015) and Mnukwa (2016) found in their studies that high employee turnover is a talent management problem at some South African municipalities. The research project had four objectives to fulfil, which will be discussed separately below.

\section{Research objective one}

The first research objective was to determine the importance of effective talent management in the Windhoek City Council in Namibia. All participants interviewed agreed that talent management is vital for an organisation to achieve its goals and objectives. However, the major challenge cited was that there is only a draft talent management strategy and framework in place, and thus the City of Windhoek Council cannot fully utilise it as they are waiting for government to formalise it.

It is presupposed that if talented employees are managed effectively, this will lead to positive outcomes for both employees and the organisation (Saurombe \& Barkhuizen, in press). Research shows that if employees are managed well, they will be greatly motivated, they will be satisfied with their jobs and they will engage effectively at the workplace (Aina \& Atan, 2020). For the organisation, talent management enhances service orientation, performance and production of high-quality products and client satisfaction (Barkhuizen \& Gumede, 2021).

\section{Research objective two}

The second objective was to determine the importance of a leadership mindset regarding talent management in local authorities. It was discovered that the leadership mindset regarding talent management is crucial for the success or failure of an organisation. Poor leadership and a lack of sound mindset and commitment to talent will negatively affect talent management in organisations (Saurombe et al., 2017). Participants highlighted that talent management is important, but they have not had an opportunity to practise it fully because it is not formalised. Adzido et al. (2015) concur that many executives do not have ample time to strengthen talent pools and are also not trained on how to develop, mentor and nurture talent. Furthermore, the Horton (2016) study showed that if management lacks commitment towards talent management practices, there will be gaps in workforce planning, talent acquisition and development.

\section{Research objective three}

The third objective was to determine how effective the current recruitment strategy of the Windhoek City Council in Namibia is. Unfortunately, it was also discovered that because of the non-formalisation of the talent management framework or policy at the City of Windhoek Council, there is, therefore, no formalised recruitment strategy except the procedures given by government according to the local authorities act. In as much as recruiting the right people with the right qualifications and talent is concerned, it seems the City of Windhoek Council's human resources personnel hands are tied as they cannot be flexible in their recruitment strategies. To support the importance of having recruitment strategies, Maheshwari and Haque (2020) and Jackson and Schuler (2017) argued that attraction and selection of talent require a flexible and well-designed competency-based recruitment system for various sections of workforce.

\section{Research objective four}

The fourth and final objective was to determine how effective the current talent retention strategy of the Windhoek City Council in Namibia is. There is also no talent retention strategy in place. However, it was found out that there are systems in place at the City of Windhoek Council that ensure a low staff turnover. They have excellent fringe benefits, competitive salary and career development initiatives that make employees stay longer at the workplace (Saurombe \& Barkhuizen, 2020).

Conversely, Mnukwa (2016) found out that the Sisonke District Municipality had many talent management challenges such as failure to retain key talent and lack of career 
management strategies. All these challenges were connected to poor motivation strategies such as low remuneration packages, organisational commitment and employee engagement (Namweda, 2017). Their recommendation was for the municipality to devise strategies that would recognise efforts of employees as well as retain talented employees for longer periods.

Additionally, Mahlahla (2018) concurred that talent management is very vital in retaining high performing employees. If talent management is not implemented effectively, it can have negative bearing that can pose a challenge on both performance and retention of employees. Both retention and transference of critical skills are important in enhancing quality service delivery for the public sector (Masale et al., 2021). The results of Mahlahla's (2018) study showed that employees were willing to leave the Masvingo City council if they got better offers elsewhere. Thus, the study recommended that retention strategies should be on a commitment basis to encourage employees to be committed and develop further as well as for the organisation to perform better.

\section{Practical implications}

The findings of this research have important practical implications for municipalities. The City of Windhoek Council should realise the importance of speeding up the process of formalising the talent management framework as it might lose talented pool in the foreseeable future to other competitive organisations. Business is evolving and there is a need to keep in pace with new human resource developments to develop and retain critical skills personnel who will assist in offering quality services to the community and residents at large. Management of the City of Windhoek Council should push for formalisation and implementation of the talent management framework or policy for betterment of the organisation.

\section{Limitations and recommendations}

Because of the small sample size, the findings of this study are not generalisable to the general population, which is all municipalities in Namibia. The findings of this research study are only applicable to the Windhoek City Council. Secondly, because of time and financial constraints, the data were collected at one point in time that limits the research in terms of lacking observation/investigation over a longer period.

Future research should be done in other cities so that findings can be compared. In addition, employees from other departments can also be interviewed to find out their perceptions about talent management. The findings of this research can be used to develop best talent management practices such as recruitment, development and retention strategies, which can be used to enhance recruitment and retention of employees in municipalities.

\section{Conclusion}

This research highlighted the importance of talent management practices and the importance of leadership mindset as well as importance of recruitment and retention strategies. If individuals' talents are not harnessed because of poor leadership and a lack of sound mindset and commitment to talent, this will negatively affect talent management in organisations. Thus, the findings of the study challenge the government to formalise the draft talent management policy at municipalities to help municipalities remain competitive by attracting, developing, retaining and rewarding talented employees. The findings of this research should encourage the City of Windhoek municipality to engage in serious dialogue with government authorities to enhance better talent management practices within the organisation.

\section{Acknowledgements}

The authors have no additional contributors to acknowledge.

\section{Competing interests}

The authors declare that they have no financial or personal relationships that may have inappropriately influenced them in writing this article.

\section{Authors' contributions}

This article was adapted from the master's research of S.N.S. who executed and wrote the article, whilst M.D.S. was the study leader and provided conceptualisation guidelines and editorial inputs.

\section{Ethical considerations}

The authors obtained permission to conduct the research from the manager of organisational and human resources development at the City of Windhoek Council and further, ethical clearance from the Southern Business School's research ethics committee to conduct the study was obtained, prior to data collection and the ethical clearance was valid during the entire duration of the data collection phase.

\section{Funding information}

This research received no specific grant from any funding agency in the public, commercial, or not-for-profit sectors.

\section{Data availability}

The original data from which the results of this article were analysed and delineated are available in the researchers' electronic database.

\section{Disclaimer}

The views expressed in the submitted article are the researchers' own and not an official position of the researchers' affiliated institution or funder. 


\section{References}

Adzido, R.Y.N., Dzogbede, O., Kamasah, V.Y., \& Dzineku, W.K. (2015). Assessing the mutual benefits of investing in staff training and development. Internationa Journal of Education and Research, 3(3), 641-656.

Aina, R.A., \& Atan, T. (2020). The impact of implementing talent management practices on sustainable organizational performance. Sustainability, 12, 8372 https://doi.org/10.3390/su12208372

Barkhuizen, E.N., \& Gumede, B. (2021). The relationship between talent management, job satisfaction and voluntary turnover intentions of employees in a selected government institution. SA Journal of Human Resource Management, 19(0), a1396. https://doi.org/10.4102/sajhrm.v19i0.1396

Bengtsson, M. (2016). How to plan and perform a qualitative study using content analysis. NursingPlus, 2, 8-14. https://doi.org/10.1016/j.npls.2016.01.001

Braun, V., \& Clarke, V. (2021a). Conceptual and design thinking for thematic analysis. Qualitative Psychology, 8(1), 2-22. https://doi.org/10.1037/qup0000196

Braun, V., \& Clarke, V. (2021b). To saturate or not to saturate? Questioning data saturation as a useful concept for thematic analysis and sample-size rationales. Qualitative Research in Sport, Exercise and Health, 13(2), 201-216. https://doi. Qualitative Research in Sport, Exercise
$\mathrm{org} / 10.1080 / 2159676 \mathrm{X} .2019 .1704846$

Brewerton, P., \& Millward, L. (2018). Organisational research methods. London: Sage.

Bryman, A., Bell, E., Hirschsohn, P., \& Du Toit, J. (2017). Research methodology business and management contexts (8th ed.). Cape Town: Oxford University Press.

Bwowe, P.W. (2015). Crafting strategies to improve talent management in selected South African Municipalities. Unpublished doctoral thesis. Mafikeng Campus. North-West University.

Chilvers, R., Richards, S.H., Fletcher, E., Aylward, A., Dean, S., Salisbury, C., \& Campbell, J. (2019). Identifying policies and strategies for general practitioner retention in direct patient care in the United Kingdom: A RAND/UCLA appropriateness method panel study. BMC Family Practice, 20, 130. https://doi.org/10.1186/s12875-0191020-x

Guest, G., Bunce, A., \& Johnson, L. (2006). How many interviews are enough? An experiment with data saturation and variability. Field Methods, 18(1), 59-82. https://doi.org/10.1177/1525822X05279903

Hadi, M.A., \& Closs, S.J. (2015). Ensuring rigour and trustworthiness of qualitative research in clinical pharmacy. International Journal of Clinical Pharmacy, 38(3), 641-646. https://doi.org/10.1007/s11096-015-0237-6

Hanns Seidel Foundation. (2018). Regional and local government: Know you government. Factsheet Series No. 6 of 8. Cape Town: Hanns Seidel Stiftung.

Horton, M. (2016). Talent management and its links to leadership and management development. University of Bristol. IOSR Journal of Business and Management, 18(12), 66-73

Jackson, S.E., \& Schuler, R.S. (2017). Human resource planning: Challenges for industrial/organisational psychologists. American Psychologist, 45(2), 223-239. https://doi.org/10.1037/0003-066X.45.2.223
Korstjens, I., \& Moser, A. (2018). Series: Practical guidance to qualitative research. Part 4: Trustworthiness and publishing. European Journal of General Practice, 24(1) 120-124. https://doi.org/10.1080/13814788.2017.1375092

Mabope, N.C. (2018). Strategies and practices for effective talent management in the Mangaung Metropolitan Municipality. Unpublished master's dissertation. Central University of Technology.

Maheshwari, N., \& Haque, M.M. (2020). A role of competency-based recruitment screening: A case study on Indian manufacturing unit. International Journal of Indian Culture and Business Management, 20(4), 467-487. https://doi. org/10.1504/IJICBM.2020.108919

Mahlahla, L.T. (2018). The impact of talent management on employee performance and retention strategies: A case study of Masvingo City Council in Zimbabwe. Unpublished Master thesis. Durban University of Technology.

Masale, R., Barkhuizen, E.N., \& Schutte, N.E. (2021). Exploring the determinants of an organisational talent culture for a Botswanan local government institution. Acto Commercii, 21(1), a892. https://doi.org/10.4102/ac.v21i1.892

Mnukwa, N. (2016). Employee turnover and retention in South African municipalities: The case of Sisonke District Municipality. Unpublished master's dissertation. University of Kwa-Zulu Natal.

Namweda, I.N. (2017). Retention of employees in the Department of Transport in the Ministry of Works and Transport in Namibia. Unpublished master's dissertation. University of South Africa.

Nguwi, M. (2015). Zimbabwe: Time to rethink employee engagement. Financial Gazette. All Africa Global Media. Retrieved from https://allafrica.com/stories/ 201505071277.htm

Sareen, P., \& Mishra, S. (2016). The study of talent management and its impact on performance on organisations. Noida: Amity Business School, University of Noida.

Saurombe, M.D., \& Barkhuizen, E.N. (2020). A talent value proposition for academic staff in a South African HEl. Journal of Global Business and Technology, 16(2), 85-102.

Saurombe, M.D., \& Barkhuizen, E.N. (in press). Talent management practices and work-related outcomes for South African academic staff. Journal of Psychology in Africa, 32(1), 1-14. https://doi.org/10.1080/14330237.2021.2002033

Saurombe, M.D., Barkhuizen, E.N., \& Schutte, N.E. (2017). Determinants of a talent life cycle for academic staff in a higher education institution. Internationa Journal of Business and Management Studies, 6(2), 279-294. http://www. universitypublications.net/ijbms/0602/pdf/P7RS296.pdf

Schlechter, A.F., Syce, C., \& Bussin, M. (2016). Predicting voluntary turnover in employees using demographic characteristics: A South African case study. Acto Commercii, 16(1), 1-10. https://doi.org/10.4102/ac.v16i1.274

Spreitzer, G.M., Cameron, L., \& Garrett, L. (2017). Alternative work arrangements: Two images of the new world of work. Annual Review of Organizational Psychology and Organizational Behavior, 4, 473-499. https://doi.org/10.1146/annurevorgpsych-032516-113332

Sutton, J., \& Austin, Z. (2015). Qualitative research: Data collection, analysis, and management. CJHP Research Primer Series, 68(3), 226-231. https://doi.org/ 10.4212/cjhp.v68i3.1456 